\title{
O manto de aporias: cultura, território e barroco na dinâmica socio-histórica do Estado de Minas Gerais
}

\author{
Anelito de Oliveira*
}

A relação entre cultura e território é estruturante da relação entre produção literária e barroco num dos lugares que constituem o alicerce do Estado-nação brasileiro: as Minas Gerais (ÁvilA, 1967; CANDIDO, 1981; MAXwELL, 1989, 2000). Mas este fato, muito longe de resolver a questão do barroco já tão debatida, complicaa fundamentalmente, já que nem cultura nem território são realidades conceituais suficientemente claras, resolvidas, como demonstram estudos ainda recentes de Homi Bhabha $(1998$, 2011), no encalço de explorações que, agudizadas pelo desconstrucionismo derridiano, remontam a Raymond Williams (1969) e ao Michel Foucault de 1967 (2009, p. 411-422), instigado pela questão do espaço. O manto de aporias, digamos, que encobre a "idea of culture" (EAGLETON, 2013), acaba por complicar tudo que dela é aproximado, como se vê claramente na articulação entre cultura e território. A operacionalização razoável dessa articulação depende, em primeiro lugar, não apenas de uma definição didática de termos - o que é cultura, o que é território -, mas da formulação de um problema com a contribuição desses termos. Desviou-se desse problema ao longo de grande parte da tradição de estudos sobre o barroco, um desvio que resultou e continua resultando em generalização e simplificação: cultura barroca, território barroco, literatura barroca etc. Assim, dizer que as Minas Gerais dos séculos XVII e XVIII constituem um território cultural barroco corresponde a um desvio, senão já uma suspensão, do problema mesmo, que é a relação antagônica, conflituosa, entre cultura e território nesse espaço.

Cultura e território não se identificam substancialmente a ponto de serem sinônimos, uma dimensão não é totalmente a outra, como transparece no sintagma "barroco mineiro" estampado no livro de Lourival Gomes Machado (1991), em que "barroco" soa como índice de cultura e "mineiro" como índice de determinado território. A articulação harmoniosa dessas duas dimensões, ao se tratar do Barroco, parece se sustentar numa indiferença, relativa ou total, aos campos de conhecimento que aprofundaram, respectivamente, as duas noções: a antropologia e a geografia (LÉvi-STrauss, 1982; SANTOS, 1996). Logo, se, em termos antropológicos,

Doutor em Literatura Brasileira e professor na Universidade Estadual de Montes Claros (Unimontes), Montes Claros, MG, Brasil. E-mail: anelitodeoliveira@gmail.com 
a cultura não se restringe aos objetos artísticos, o território, em termos geográficos, não significa todo o espaço físico: se a cultura corresponde a uma totalidade de fazeres humanos, o território corresponde a uma segmentação do espaço físicosocial. Evidentemente que a recorrência a essas distinções contemporâneas só se justifica, quando se trata de barroco, em função do estatuto de objeto conceitual do próprio barroco há muito consolidado, objeto cuja condição de possibilidade no nosso tempo presente é a sincronia, o que, malgrado toda a controvérsia que possa suscitar (CAMPOS, 1989), constitui um horizonte hermenêutico bastante fértil. Lidar com conceitos de cultura e território praticados pela antropologia e geografia contemporâneas significa apreender o barroco a partir de uma perspectiva sincrônica. Esta, sem ignorar a perspectiva diacrônica, possibilita o resgate e inscrição do estilo historicamente vinculado ao espaço ibérico do século XVII na dinâmica sociocultural do Ocidente moderno como um todo.

A complexidade do objeto conceitual barroco em geral - e do chamado "barroco mineiro", que aqui é o caso - revela-se, pois, assentada, originariamente, na relação contraditória entre cultura e território, entre a dimensão da totalidade, correspondente à cultura, e a dimensão da especificidade, correspondente ao território. Um aspecto comum a essas duas dimensões é o fato de serem ativas, resultantes da "vida ativa", nos termos de Hannah Arendt (2009, p. 15-26), de sujeitos históricos, de ações demandadas, sobretudo, pela vida material da coletividade, ações interessadas, políticas, portanto, como podemos percebê-las a partir do ponto de vista teórico de Pierre Bourdieu (2014, p. 137-156). E um aspecto incomum é o fato de os interesses que movem a cultura não serem exatamente os mesmos que movem o território, o fato de a produção da cultura ser presidida por interesses diversos, conflitantes, daqueles que presidem a produção do território em Minas Gerais. Disso resultaria, no limite, a impossibilidade de haver uma única "voz de Minas", um consenso identitário embasado numa harmonia entre as muitas dimensões históricas de um mesmo lugar, como José Murilo de Carvalho (2005, p. 56) sustenta em sua réplica ao ensaio controverso de Alceu Amoroso Lima (2000) originalmente publicado em 1944. Compreender esses interesses passa a ser, assim, o caminho para a compreensão do antagonismo entre cultura e território, a razão da desarmonia constitutiva da relação entre essas duas dimensões. Tal compreensão não é tarefa simples, na medida que os interesses objetivamente visados são revestidos de ideologia, cuidadosamente racionalizados, estrategicamente mascarados, portanto.

Em linhas gerais, os interesses que movem a cultura no sentido "ilustrado", nas Minas Gerais "iluminadas" do século XVIII, conforme explorado por autores como Sérgio Paulo Rouanet (1992, p. 329-345), são, num primeiro nível, de natureza estética, fundamentados num ideal de beleza. Por outro lado, os interesses que movem o território são, também num primeiro nível, de natureza econômica, fundamentados num ideal de riqueza, de acumulação capitalista. Mas a questão se complica, já nesse nível elementar, à medida que, intensificando o Renascimento, conforme a perspectiva assentada a partir de 1888 com o texto de Heinrich Wölflin (1989), o Barroco apresenta o estético como intrinsecamente imbricado no econômico, a 
beleza como regra ("nomos") da casa ("oikos") também, como José Antonio Maravall (1997) se empenhou em elucidar. Uma cidade, uma igreja, uma praça, uma obra escultórica, pictórica, musical, poética, produções derivadas tanto de interesse estético quanto econômico, resultam, simultaneamente, de pulsações que se dão nas esferas da cultura e do território. Mas isso não significa que se trata de um mesmo interesse, que cultura e território tornam-se, nesse processo, uma mesma dimensão estético-econômica, uma unidade configurada graças a um acordo entre partes opostas envolvidas no processo histórico. Pode-se falar, evocando Néstor Garcia Canclini (1998), na hibridação de valores culturais e territoriais, estéticos e econômicos, como um artifício, uma complicação, que constitui exatamente a superfície barroca, uma "ilusão" americana, como Affonso Ávila (2004, p. 77-102) refletiu em diálogo surpreendente com A ilusão americana, o polêmico ensaio de 1893 de Eduardo Prado, que dificulta a compreensão do barroco.

A distinção entre cultura e território se torna possível à medida que consideramos os sujeitos históricos numa posição de ascendência em face dos objetos produzidos, como sujeitos efetivamente produtores desses objetos, o que implica, evidentemente, uma perspectiva materialista sobre a história. Os sujeitos que produziram originariamente a cultura e o território em Minas Gerais, ao longo dos séculos XVII e XVIII, eram movidos, claro, por interesses diferentes porque eram marcados por necessidades diferentes, derivadas de lugares sociais diferentes (RESENDE, 2007, p. 25-53). O território resulta da necessidade de nativos encontrarem meios de sobrevivência, ao passo que a cultura resulta da necessidade do colonizador português de ordenar, segundo seus parâmetros civilizatórios, o espaço social. No centro da dinâmica produtiva do território está a questão do trabalho, ao passo que no centro da dinâmica produtiva da cultura está a racionalidade, que se impõe, por evidente razão ideológica, sobre a totalidade espacial. A produção de um território próprio, distinto dos demais que o circundam, um "território mineiro", foi possibilitada, desde o início, pelo trabalho - indígena, bandeirante, sertanejo, escravo, no período colonial - de uma maioria negra, inclusive, que habitava o "espaço mineiro" (LiBBy, 2007, p. 406-438). A produção de uma "cultura mineira", por sua vez, foi possibilitada, também desde o início, pela atuação de uma elite letrada - vinculada, no período colonial, à Coroa portuguesa e, em grande parte, ao Estado, a partir do momento em que este, com a independência do país e, mais ainda, com o fim da Monarquia e instauração da República, ganha seus contornos de Estado-nação, todo um processo que teve seu ápice na Ouro Preto do final do século XIX, conforme abordado com precisão por Fernando Correia Dias (2001).

Desses elementos históricos não só derivam as especificidades do território e da cultura em Minas Gerais, mas, sobretudo, a razão do profundo antagonismo entre essas duas dimensões. A maioria-povo, responsável pela produção material do território, é dominada pela minoria-elite, supostamente única responsável pela produção da cultura, que assim se torna referência de dominação pela via do mascaramento da realidade, das desigualdades sociais. Esse antagonismo não é, naturalmente, exclusividade de Minas Gerais, mas tem sua "cor local" evidente no 
início do processo de "invenção" das Minas Gerais, conforme o ponto de vista de Francisco Eduardo de Andrade (2008): a cultura mineira é, na sua origem, produzida com o trabalho dos escravos mineradores, viabilizada pelo ouro e o diamante resultantes desse processo. Sem o trabalho forçado, obviamente, não haveria as hoje consideradas "cidades históricas", não haveria igrejas, altares, adros, esculturas, Casa da Ópera, Casa de Câmara e Cadeia, construções civis as mais diversas, obras culturais edificadas estruturantes de um território que, por sua vez, estrutura, de modo decisivo, uma nação. Neste fato está, sem dúvida, o estímulo fundamental para a naturalização contemporânea da relação entre cultura e território, mas essa naturalização dissimula uma "violência simbólica", nos termos de Pierre Bourdieu e Jean-Claude Passeron (2008, p. 21-90) que as próprias obras culturais, paradoxalmente, denunciam.

A primeira grande obra cultural produzida com o trabalho da maioria subalterna em Minas Gerais foi de caráter urbanístico: os caminhos, os arraiais, as freguesias, as vilas e, finalmente, a única cidade que a capitania teve no período colonial, Mariana (Moraes, 2007, p. 55-85). O urbanismo ocupa, desde o final do seiscentos, uma posição ambivalente: é tanto uma questão de ordem territorial quanto de ordem cultural, na medida em que atende a interesses econômicos de uma maioria segundo preceitos estéticos, modos de se sentir, de uma minoria dominante. Inicialmente, no período que vai do adentramento da Capitania até as primeiras descobertas de ouro, esses interesses se harmonizavam, como se pode inferir dos estudos pioneiros de Affonso Ávila (1967). Preponderava, entre os exploradores aventureiros, uma perspectiva econômica "selvagem", interessada apenas na exploração dos recursos naturais da terra nova, em conformidade com o projeto civilizatório como um todo, tal qual narrado por autores como Darcy Ribeiro (1997). As inflexões monstruosas desse processo, a violência que o caracteriza, aparecem especialmente quando se tem em vista a região dos Gerais, tema de pesquisas mais recentes (ANASTASIA, 2005). A desarmonização desses interesses surge à medida que o aspecto estético passa a fazer parte do aspecto econômico, à medida que as vilas passam a ser visivelmente enriquecidas por construções dignas da quantidade enorme de ouro extraída das minas. Ao ritmo acelerado da mineração, desenvolve-se, sobretudo em Vila Rica, o complexo urbanismo barroco, com suas diversas referências culturais, religiosas e étnico-raciais (GARCIA, 2005; FonsECA, 2011). Ao expressar de modo contundente o antagonismo entre cultura e território, esse urbanismo funda uma vida mental igualmente antagônica em Minas Gerais. A produção artístico-literária, marcada pela crise do sujeito, como se vê de Cláudio Manoel da Costa a Carlos Drummond de Andrade (SouzA, 2011; OliveirA, 2017), é exemplo notável desse antagonismo.

Objeto produzido por uma coletividade, esse urbanismo tem em Antonio Francisco Lisboa, o Aleijadinho, não apenas sua maior referência, mas sua referência problemática. Em torno de Aleijadinho - e da sua obra - não há consenso ainda depois de 200 anos de sua morte, ocorrida em 1814, mas, pelo contrário, há muito dissenso, que nos leva diretamente a uma situação política à medida que temos 
em vista o dissenso como traço característico da política, conforme postulado por Jacques Rancière (2006, p. 367-383). Aleijadinho é tanto um caso territorial, no sentido de agente de um processo histórico que visou ordenar o espaço comum, quanto um caso cultural, no sentido de um artista movido pelo incessante desejo de criar obras de arte, referência de uma postura ambivalente que solicita compreensão como tal, sem simplificações. $O$ fato de não ter se restringido a um tipo de sujeito nem a outro, nem a trabalhador comum nem a artista incomum, acabou por fazer do arquiteto, escultor e entalhador afrobrasileiro um caso significativo para se compreender a convergência e divergência, ou convergência divergente, entre as dimensões cultural e territorial. A não restrição a um tipo de sujeito não se deveu, evidente, a uma decisão de Aleijadinho, mas ao fato de a especialidade, a limitação a um determinado ofício, não ser um valor propriamente dito do seu tempo, bem como não ser algo permitido a um subalterno, com suas qualidades étnico-raciais. As duas dimensões do sujeito - territorial e cultural - convergem quando se trata da obra arquitetônica, em função de convenções metodológicas e necessidades urbanas, e divergem, quando se trata da obra escultórica. Nesta, a "particularidade" do artista, lembrando a perspectiva estética de Georg Lukács (1967), apresenta-se com veemência, desfigurando, recriando, a "Idea" (PANOFsKy, 200o) universal, de modo que a obra artística acaba por se configurar, sem que isso seja uma intenção estética, como inquietante tradução cultural.

O Santuário do Bom Jesus de Matozinhos (1757-1772), em Congonhas do Campo, expõe, de modo incisivo, essa convergência e divergência, ao mesmo tempo, entre as dimensões cultural e territorial em Aleijadinho: no seu todo - a igreja, as capelas, o adro, a praça -, trata-se de obra objetivamente territorial, mas, em cada parte - os Profetas esculpidos em pedra-sabão, as esculturas em madeira dos Passos da Paixão -, trata-se de obra objetivamente cultural. Isso significa que a totalidade de sentido que vemos ali é expressão de uma coletividade, enquanto a especificidade, que também ali vemos, é expressão de uma individualidade. Esta indica o sujeito que, na visão eufórica de Lezama Lima (1988, p. 104-106), empenhou a própria vida no trabalho audacioso de fundação da cidade, chegando a se converter mesmo no "mistério gerador da cidade", afirmando, por fim, "a rebelião artística dos negros" no espaço latino-americano. Claro que a relação que se estabelece entre as duas dimensões - territorial e cultural - nesse momento radical, decididamente ambicioso, da produção do urbano, não exatamente da produção de um determinado objeto artístico, não é de base hierárquica: o comum, o território, não é mais ou menos importante que o incomum, o cultural, e vice-versa, pelo simples fato realmente de que o que está em questão é a afirmação de uma ordem discursiva superior, a ordem da Coroa Portuguesa, processo em que a materialização exuberante, barroca, tão intensa quanto extensa, da fé católica constitui um dispositivo eficaz de dominação pela via contrarreformista, em oposição frontal aos valores preconizados pelo protestantismo, como se sabe.

Pode-se pensar de modo bastante razoável, em face das ações materiais de cunho civilizatório nas Minas coloniais, que o territorial e o cultural encontram-se 
aprioristicamente equiparados pelo ponto de vista da Coroa, que nenhum é tratado de modo exclusivista, como portador de mais valor do que o outro, que são objetos unificados e utilizados em nome de um interesse maior, de natureza política, que se acentua radicalmente com a ascensão do Marquês de Pombal a partir de 1756 (Teixeira, 1999). Mas é inegável que, diante de toda a produção artísticourbanística - e, especialmente, do Santuário do Bom Jesus de Matozinhos - em que Aleijadinho está altivamente envolvido, levando às últimas consequências o seu processo criativo, é perceptível uma tensão, índice de uma singularidade que emerge da universalidade como uma espécie de tradução cultural (BHABHA, 1998, p. 292-325) impulsionada por elementos constitutivos do local do sujeito, aquilo que, em última instância, fez e continua a fazer do artífice-artista uma referência problemática, de paradoxal afirmação-negação ideológica. A tensão, a desarmonia entranhada no produto final, desdiz, por si só, esse produto - o território, a cultura - como algo resolvido, ou melhor: o produto como algo derivado de um horizonte estético, vinculado a um ideal de beleza clássico que havia ressurgido, neoclássico, naquele fim de século XVIII com a "Aufklärung". Território e cultura aproximam-se na obra de Aleijadinho agonicamente, de modo conflituoso, revelando, assim, os antagonismos que presidem a produção do território e da cultura: uma produção forçada, obrigada, contra a vontade daqueles que nela atuam, a gente escrava, para quem o trabalho é um martírio.

O fato de ser filho bastardo de um branco português com uma negra africana não tirou Aleijadinho da condição de gente escrava, mas antes acabou por inscrevê-lo de modo ainda mais agônico nesta condição, marcado pela ambiguidade ontológica, pelo ser e não ser ao mesmo tempo negro e não negro. Trata-se de ambiguidade responsável pelo caráter decididamente complicado, dobrado, perturbador do "discurso reto", da sua obra. Resultante de premências práticas, de necessidades impostas à vida social de cima para baixo, sua obra apresenta, pela primeira vez, o modo altamente complexo como se dá a "negociação", no sentido fértil trabalhado por Homi Bhabha (1998, p. 55), do registro de valores identitários negros, vinculados ao povo africano, em terras americanas. Hoje, na contemporaneidade inaugurada pelos modernistas dos anos 1920, toda uma tradição interpretativa, uma massa discursiva de vária radicação crítica, já está estabelecida como sendo uma espécie de real da obra de Aleijadinho, compreendida como cultura em stricto sensu, como objeto artístico, beleza produzida. Mas a reflexão sobre essa obra a partir de um princípio dialógico, considerando-a como elemento vivo dentro de uma dinâmica sociocultural de uma determinada região, mais ainda, como significação estruturante de todo um campo barroco, acaba por nos colocar em face de um problema aguçado pela própria tradição que resgatou e valorizou Aleijadinho a partir da polarização de verdades socio-historiográficas e estético-filosóficas: o real da obra é de ordem espacial, o que a investe de uma singularidade política.

À medida que é produzida no e com o espaço físico mineiro, como ação ordenadora desse espaço, a obra de Aleijadinho não é totalmente compreensível a partir 
de premissas radicadas somente na categoria tempo, animada especialmente pelo horizonte hegeliano. A obra espacial, resultante de questões objetivas da vida prática que se experienciava nas Minas do Ouro, impõe, para sua compreensão, uma recorrência à categoria espaço, tal como operacionalizada pela geografia humana, pautada pelo preceito de atuação constante, simultânea, das coisas, formas, tempos (SANTOS, 1991, p. 10), numa dinâmica epistemológica não historicista. A complexidade da obra, neste caso, explicar-se-ia em função da complexidade do espaço total de que é parte intrínseca, não a única parte, obviamente, mas uma das partes, uma parte mais valiosa pela ascendência cognitiva, pode dizer-se, hermenêutica, que tem em relação às demais. A obra em geral do artífice crioulo, mas especialmente a arquitetônico-urbanística, constitui um processo de interpretação inaugural de um espaço físico então bruto, compacto, desprovido de inteligibilidade. Cada constructo arquitetônico, da planta-baixa ao acabamento, confere ao espaço das Minas uma determinada inteligibilidade, constitui movimento, a um só tempo, de leitura e escrita do espaço bruto, uma "Destruktion" da pureza originária do lugar que resulta, no limite, num devir-barroco desse espaço, isto é, numa identidade antagônica que até então não havia decididamente, interessadamente - tudo estava vazio, tudo era lacuna.

Ao nos voltarmos para a produção que constitui o sujeito Aleijadinho, cuja existência é denunciada pela obra, compreendemos que a inteligibilidade que ali se revela não é inventada por ele, mas praticada por ele num evento criativo dialógico em que o espaço peculiar das Minas - montanhoso, irregular, acidentado - desempenha um papel ativo, condicionando de várias maneiras o processo - material de construção, mão de obra, equipamentos, limitação ideológica. A essa atividade do espaço, ao fato de que atua como objeto e sujeito nesse evento criativo, é que se pode atribuir a "particularidade" estética que essa inteligibilidade - aprendida pelo artífice com seu pai, como se sabe - acaba por revelar, a aparente degeneração dos cânones clássicos, todo o mal gosto, a deficiência, a feiura, a falta de genialidade, apontada pelos viajantes europeus no século XIX. Trata-se de uma "particularidade" estética que se define a partir de fora, do entorno, daquilo que está no espaço circundante, da gama de coisas, da totalidade material que constitui aquele espaço onde Aleijadinho se encontra, um espaço do trabalho, da extração de minérios, onde determinado território está sendo talhado, uma terceira dimensão, "dinâmica", resultante da relação tensa entre o sujeito e seu objeto imediato, o espaço físico.

A coletividade de que Aleijadinho faz parte, e com a qual ele vai construir uma identidade urbana própria, não pensa, no sentido escolástico, e sim age, não por uma escolha, mas por uma obrigação, e este dado tem um impacto decisivo sobre a relação entre cultura e território em Minas Gerais. O que esse sujeito histórico, de que Aleijadinho constitui a referência, produz não é um pensamento, mas uma ação; não é algo de natureza teórica, mas, sim, de natureza prática, que visa atender a uma necessidade da vida comum, qual seja: ordenar semanticamente o espaço compartilhado, construir, a partir da relação material com o espaço, o terri- 
tório. Todavia, essa distinção, que se sustenta firmemente até fins do século XIX, acaba por cair por terra a partir das duas primeiras décadas do século XX, quando se processa a reviravolta hermenêutica modernista nos grandes centros ocidentais, de que os modernistas paulistas e mineiros são protagonistas no Brasil. Rompe-se com o olhar que distinguia radicalmente teoria e prática, mas persiste mesmo assim uma ascendência, para não dizer uma supremacia, da cultura sobre o território que atesta uma linha de permanência da racionalidade que ordenava o espaço social ibérico no século XV, com seus desdobramentos subsequentes nos séculos XVI, XVII e XVIII.

Como se sabe, a cultura, de acordo com essa racionalidade, constitui um saber estratégico construído com a finalidade específica de submeter bárbaros a civilizados, especialmente em terras distantes, em novos mundos descobertos. O fato de esses bárbaros, ao longo dos processos civilizatórios que se deram nas Américas, desempenharem tarefas racionais, demonstrando capacidade intelectual, não significou seu reconhecimento como civilizados - eram apenas animal laborans, para recordar uma vez mais Hannah Arendt (2009, p. 31). O reconhecimento dos bárbaros, dos crioulos, como civilizados significaria reconhecê-los como portadores de cultura, de uma série de valores históricos, estéticos, éticos, religiosos e ideológicos que distinguiam o colonizador e autorizava seu projeto de dominação. Assim, o que o sujeito - coletivizado, senão coletivo - Aleijadinho fez não poderia ser percebido e apreciado senão como trabalho esforçado de um operário exótico, conforme a Carta remetida à Coroa em 1790 pelo vereador de Mariana Joaquim da Silva (1997). Reconhecer a obra de Aleijadinho como expressão cultural significaria reconhecer racionalidade humana, europeia, não só num subalterno, mas em toda aquela coletividade subalterna que operava com ele, que com ele compartilhava a ordenação de um novo território. A ideia de cultura no século XVIII era um traço distintivo do civilizado apenas, e assim permanece, substancialmente, nos séculos posteriores, XIX e XX.

Não sendo um problema propriamente dito de cultura em pleno século XVIII, tampouco de arte barroca, compreensões já dos séculos XIX e XX, Aleijadinho torna-se, paradoxalmente, o maior caso de cultura do barroco, no sentido postulado por Maravall já aludido, em Minas Gerais, no país e na América Latina. Isso em virtude do urbanismo, pelo que produziu nas chamadas cidades históricas mineiras, pelo fato de sua obra não apenas ser possibilitada pelo advento da cidade, mas ser a própria cidade, para lembrar Giulio Carlo Argan (2005) replicando Mumford Lewis. Deve-se, sobretudo, a um horizonte territorial - a questão urbana -, a consagração de Aleijadinho, que não significa, por outro lado, unanimidade positiva no universo crítico-acadêmico, onde o acervo enorme de trabalhos científicos cumpre, acima de tudo, o papel de evidenciar que a obra imensa do mestre permanece como uma questão aberta, como acaba de sugerir artigo de Silviano Santiago (2017) sob o título "A construção de Aleijadinho". No curso específico da dinâmica sociocultural mineira, Aleijadinho surge como referência primordial de uma relação problemática, muito conflituosa, que podemos entender como sendo 
de ordem epistemológica, ou seja, pertinente à relação entre sujeitos (pesquisadores diversos) e objeto de conhecimento (Minas Gerais). A grande referência dessa relação é o historiador Theóphilo Feu de Carvalho (1934), o qual, com a autoridade conferida pelo cargo de diretor do Arquivo Público Mineiro (1920 a 1936, com os intervalos de 1923 a 1925 e 1928 a 1932) - instituição estruturante da memória cultural do Estado, criada em 1893 -, contesta, embasado na absolutização do documento escrito, a autoria de muitas obras atribuídas ao artífice-artista.

O trabalho polêmico de Feu de Carvalho expressa, sobretudo, sua preocupação, em consonância com a historiografia tradicional, com a necessidade de um critério rigoroso para a preservação dos documentos do passado mineiro. Seu argumento não é movido por preocupação de ordem estética, mas por preocupação de ordem institucional, animado pela obsessão de controle do Estado moderno em fase de crise terminal da "República velha" e consequente "Revolução de 30 ". Daí que Feu de Carvalho baseie-se em recibos de pagamento feitos a Aleijadinho, reconhecendo como sendo de sua autoria apenas aquelas obras que lhe foram encomendadas e para cuja execução foi remunerado, conforme documentos comprobatórios. Tal argumento, por mais elementar, grosseiro até, que tenha parecido a olhos clínicos daquele tempo - e mais nos pareça hoje sob a égide não mais da "história nova", mas já de uma pós-história -, acabou por perturbar o espaço cultural mineiro durante quase cinco décadas, de meados dos anos 1920 a meados dos anos 1960. Contribuiu, pela via negativa, para a colocação de Aleijadinho no centro de uma disputa de poder simbólico que, ao ultrapassar as fronteiras do Estado, revelou a centralidade do barroco produzido nas Minas no que diz respeito à identidade cultural brasileira, como argumenta Gilberto Freyre (1947, p. 277-314) numa de suas conferências na Universidade de Indiana em 1944 devotadas à interpretação do Brasil. Feu de Carvalho, ao desejar restabelecer o que lhe parecia ser a verdade histórica no âmbito do patrimônio artístico-cultural, acabou por forçar o aparecimento de Aleijadinho como problema histórico vinculado à "práxis", às trocas comerciais no âmbito do simbólico (Bourdieu, 2011, p. 99-151), à cotidianidade.

$\mathrm{O}$ argumento do historiador, que evidentemente expressava perspectiva da elite sociocultural a que pertencia, encontrou seu grande entusiasta em Augusto de Lima Jr. (1942), que o articulou a interesses familiares e políticos, logrando assim, também por uma via negativa, tratar a questão cultural como parte da questão social. Nesta linha de abordagem, importa perceber, para além da questão da verdade, a qualidade interessada do movimento hermenêutico que se produz em face do objeto: o fato de Aleijadinho passar a ser visado como capital simbólico construído e operacionalizado por determinado grupo político. Ao exacerbar o argumento de Feu de Carvalho, Augusto de Lima Jr. chega a colocar em dúvida a possibilidade humana de alguém produzir uma quantidade tão grande de obras. Isso, para o polemista, tornaria razoável a possibilidade de Aleijadinho constituir apenas uma lenda estrategicamente criada por uma elite política do Estado de Minas Gerais interessada na conquista e manutenção do poder, de que a imagem capital seria a criação do Serviço Nacional do Patrimônio Histórico e Artístico Nacional 
(SPHAN) em 1937, obra da "constelação Capanema", como Helena Bomeny (2001, p. 11-35) chama os amigos do político getulista Gustavo Capanema, entre os quais Carlos Drummond de Andrade, Mário de Andrade e Rodrigo Melo Franco de Andrade. O argumento de Lima Jr., embora tenha soado inconsistente no seu tempo e soe mais absurdo ainda hoje, não deixou de repercutir e continua repercutindo no campo das artes em Minas Gerais em função também, assim como se deu com Feu de Carvalho, do lugar sociopolítico importante, distinto, ocupado pelo seu autor na sociedade mineira.

A contestação sistemática do argumento de Feu de Carvalho - é muito importante enfatizá-lo - surge fora do espaço geopolítico das Minas Gerais estabelecido a partir do século XVIII. Se se considera que a autonomia da capitania das Minas do Ouro, a partir da cisão com a capitania de São Paulo, deu-se apenas a partir de 1721 (BoschI, 1998), pode-se dizer que essa contestação tem uma espécie de motivação na geopolítica originária, numa percepção do objeto da polêmica - Aleijadinho - como referência de um território comum em termos regionais, objetivos, não apenas nacionais, subjetivos, referência que estimula um sentimento de responsabilidade com o Barroco, enquanto patrimônio identitário, em Mário de Andrade. Em seu ensaio sobre o escultor mineiro publicado em 1935, Andrade (1965), munido de elementos conceituais hauridos em várias disciplinas - história, estética, filosofia, psicologia, anatomia, sociologia, etnologia etc. -, logra demonstrar como se constrói uma singularidade estilística na vasta produção de Aleijadinho, como se desenvolve todo um processo estético que tem em seu centro propulsor, digamos, uma mesma personalidade. O dado específico dessa personalidade, seu traço singular, é, para o modernista, de ordem étnica, que seria responsável, tanto em sua escultura quanto em sua arquitetura, pela subversão dos modelos europeus aprendidos, pela sua originalidade, que corresponderia à autenticidade da nação brasileira. A partir dessa abordagem, precisamente, Aleijadinho deixa de ser referência de artista isolado, de um indivíduo, para ser referência da problemática que caracteriza a relação entre operadores da esfera do sensível, da aisthesis, e o seu entorno objetivo, o espaço, num território ultramarino.

Com sua intervenção num debate naturalmente difícil de se realizar, tanto em função da autoridade institucional de Feu de Carvalho quanto em função do estágio ainda precário, em termos metodológicos, da análise científica da obra de arte naquele início de século, em que se ressalta a dificuldade pertinente à questão da autoria, Mário de Andrade dá um passo decisivo, sobretudo, para alterar a relação entre autores literários mineiros então emergentes, os modernistas dos anos 1920, e o passado barroco do Estado. O ensaio fala alto ao presente da sua publicação, sendo, sem dúvida, o ponto culminante de um processo de compreensão e valorização da especificidade cultural de Minas Gerais. Esse processo teve início em 1919, com a visita que Mário de Andrade faz a Alphonsus de Guimaraens em Mariana, fato que Carlos Drummond de Andrade (1977) rememoraria em chave lírico-dramática muitas décadas depois. O segundo momento objetivo desse processo foi a excursão coletiva do grupo modernista, acompanhando Blaise Cen- 
dras, às "cidades históricas" mineiras em 1924. Também se pode considerar como parte desse processo, sem dúvida, os diálogos, via carta postal, estabelecidos por Mário de Andrade com quase todos os nomes significativos do cenário cultural mineiro dos anos 1920, 1930 e 1940, especialmente com Carlos Drummond de Andrade (2002). À luz de todo esse processo, frequentemente ofuscado pela mitificação da Semana de 22, pode-se dizer que a renovação das artes e das ideias, da sociedade e da mentalidade brasileira, configura-se de modo que implica uma percepção dinâmica da história, em oposição a uma percepção estática, uma mobilidade de olhar que coloca presente e passado em constante interlocução, tendo por referência a produção material, dotada de valor estético, que se apresenta no tecido urbano das Minas.

O modo como Mário de Andrade percebe Aleijadinho é estimulante, aos olhos dos então jovens modernistas mineiros, na medida em que o tira de uma limitação regional, de uma "camisa de força" mineira, e o inscreve num horizonte universal em função da sua particularidade, aquela mesma particularidade percebida inicialmente, pelos olhos europeus, como mau gosto. O universal, portanto, seria resultante de um procedimento estranho, próprio de um sujeito, não de um procedimento comum, seria um movimento no sentido da afirmação de valores locais. Tal movimento não se faz como negação pura e simples de valores globais, mas como conflito intenso com esses valores. A produção de algo passível de ser reconhecido como expressão da espécie humana, não apenas de um aglomerado de pessoas, tal como aparece na obra de Aleijadinho, implicaria uma relação objetiva com o local, uma inflexão no sentido de plasmar aquilo que é característico do local, que está subsumido no espaço físico-social genérico. Assim, o modernista logra estimular seus admiradores, moradores de uma Belo Horizonte recémfundada, a perceber o que estava diante deles, nas próprias Minas, como matéria bruta, digamos, de poesia, de literatura, que não deveria ser exaltada em arroubos provincianos, mas ser sensivelmente enfrentada.

Esse enfrentamento constituirá sempre, ao longo do século XX, a afirmação, por parte de produtores de objetos artístico-literários em Minas Gerais, de um a priori criativo, configurado pela obra de Antonio Francisco Lisboa, que é o da relação com o espaço urbano, a compreensão de que a produção artística corresponde a uma demanda da vida urbana. Enquanto tal, essa produção implica o envolvimento sistemático de seus produtores com a vida social, a participação interessada no processo de configuração da esfera do comum, uma certa impossibilidade de alheamento, uma espécie de engajamento natural nas questões da cidade. Os então jovens modernistas mineiros em geral, não apenas aqueles que já tinham assumido as letras como o seu campo de atuação - jovens como Milton Campos e Gustavo Capanema também, que acabaram por enveredar pela política partidária, mas que foram partícipes ativos das rodas culturais modernistas -, percebem, na esteira da compreensão que Mário ostenta, que Aleijadinho é referência de um modo de ser estético-social que caracteriza toda uma comunidade fundadora, no século XVIII, de uma identidade cultural específica de Minas Gerais, praticante de 
uma série de valores - morais, éticos, políticos, culturais etc. - que distingue a região das demais do país.

Ao lado de Aleijadinho, num mesmo tempo e lugar, como partícipes, portanto, de uma mesma comunidade, estiveram, sempre inquietos, figuras como o pintor Mestre Ataíde, o padre erudito Luís Vieira da Silva e os poetas - e operadores do direito, burocratas da Coroa - Cláudio Manuel da Costa, Alvarenga Peixoto, Silva Alvarenga e Tomás Antonio Gonzaga; como Eduardo Frieiro (1981) logrou revelar com perspicácia. Esses sujeitos históricos foram unificados, no seu tempo, pelo compartilhamento de um mesmo espaço que tinha como seu epicentro, digamos, a Vila Rica, um espaço que lhes coube, por obrigação assumida junto à Coroa, transformar num dado território, dotar de uma ordem semântica europeia, civilizada. Não se pode dizer, em face daquele contexto, que um ofício era melhor que o outro, que o ofício de projetar edificações e criar esculturas era mais importante que o ofício de escrever versos. A necessidade de produzir um território civilizado no espaço selvagem, no ignoto sertão do país, uma necessidade maior da Coroa, que assim impunha a ordem social fundamental à alta lucratividade desejada, colocava os vários artífices num mesmo nível prático, compreendia-os como sujeitos a serviço da produção de um território que seria, a princípio, uma extensão do território português daquele período, um território neoclássico, portanto.

O caráter barroco de que esse território acaba por se revestir e pelo qual é reconhecido e valorizado depois da ação dos modernistas paulistas, pode ser percebido como um malogro da "razão pura", de base iluminista, em sua relação com a história viva, produzida pelos sujeitos no local ali onde se processa sua existência cotidiana. O que Aleijadinho e os árcades produzem revela, apenas em registros diferentes, uma mesma dificuldade, para não dizer impossibilidade, de enquadramento do sujeito histórico, situado numa racionalidade definida na metrópole europeia e imposta na colônia. Trata-se de produção que não se limita, portanto, às obras de arte em si, aos produtos - às esculturas, aos escritos, aos livros etc. -, que não têm seu sentido acabado nas coisas visíveis, que constituem, mais ainda, referências de um processo mais significativo, elementos característicos de uma "produção social da escrita", nos termos de Raymond Williams (2014), de ordenamento do inteligível. O que se ressalta nessa produção, como seu objeto "dinâmico", "real", é exatamente a angústia, que passa a se apresentar, a partir da produção dos árcades e de Aleijadinho, como traço distintivo da relação entre criadores de objetos artístico-literários e espaço social em Minas Gerais.

\section{Referências}

Anastasia, Carla Maria Junho. A geografia do crime: violência nas Minas setecentistas. Belo Horizonte: Editora da UFMG, 2005. 
Andrade, Carlos Drummond de. A visita. Planejamento editorial e gráfico de José Mindlin. Fotografias de Maureen Bisilliat. São Paulo: Digital, 1977.

Andrade, Carlos Drummond de. Carlos e Mário: correspondência de Carlos Drummond de Andrade e Mário de Andrade. Rio de Janeiro: Bem-te-vi, 2002.

Andrade, Francisco Eduardo de. A invenção das Minas Gerais: empresas, descobrimentos e entradas nos sertões do ouro da América portuguesa. Belo Horizonte: Autêntica; Editora PUC-Minas, 2008.

Andrade, Mário de. Aspectos das artes plásticas no Brasil. São Paulo: Martins, 1965.

Arendt, Hannah. A vita activa e a condição humana. In: Arendt, Hannah. A condição humana. Tradução de Roberto Raposo. Rio de Janeiro: Forense Universitária, 2009.

Argan, Giulio Carlo. História da arte como história da cidade. Tradução de Luigi Cabra. São Paulo: Martins Fontes, 2005.

Ávila, Affonso. Circularidade da ilusão e outros textos. São Paulo: Perspectiva, 2004 .

Ávila, Affonso. Resíduos seiscentistas em Minas. Belo Horizonte: Centro de Estudos Mineiros, 1967. $2 \mathrm{v}$.

BhabHa, Homi. O bazar global e o clube dos cavalheiros ingleses: textos seletos. Organização de Eduardo F. Coutinho. Tradução de Teresa Dias Carneiro. Rio de Janeiro: Rocco, 2011.

BhABHA, Homi. O local da cultura. Tradução de Myriam Ávila et al. Belo Horizonte: Editora da UFMG, 1998.

Bomeny, Helena (Org). Constelação Capanema: intelectuais e políticas. Rio de Janeiro: FGV; Bragança Paulista: Universidade São Francisco, 2001.

Boschi, Caio C. (Org.). Inventário dos manuscritos avulsos relativos a Minas Gerais existentes no Arquivo Histórico Ultramarino (Lisboa). Belo Horizonte: FJP, 1998. 3 v.

Bourdieu, Pierre. É possível um ato desinteressado? In: Bourdieu, Pierre. Razões práticas: sobre a teoria da ação. Tradução de Mariza Corrêa. Campinas: Papirus, 2014 .

Bourdieu, Pierre. O mercado de bens simbólicos. In: Bourdieu, Pierre. A economia das trocas simbólicas. Organização de Sergio Miceli. Tradução de Sergio Miceli et al. São Paulo: Perspectiva, 2011.

Bourdieu, Pierre; Passeron, Jean-Claude. Fundamentos de uma teoria da violência simbólica. In: Bourdieu, Pierre; PAsseron, Jean-Claude. A reprodução: elementos para uma teoria do sistema de ensino. Tradução de Reynaldo Bairão. Petrópolis: Vozes, 2008. 
CAMPos, Haroldo de. O seqüestro do barroco na formação da literatura brasileira: o caso Gregório de Matos. Salvador: Casa de Jorge Amado, 1989.

CANClini, Néstor García. Culturas híbridas: estratégias para entrar e sair da modernidade. Tradução de Ana Regina Lessa e Heloísa Pezza Cintrão. São Paulo: Edusp, 1998.

CAndido, Antonio. Formação da literatura brasileira: momentos decisivos. Belo Horizonte: Itatiaia, 1981. $2 \mathrm{v}$.

Carvalho, (Theóphilo) Feu de. Aleijadinho. Belo Horizonte: Edições Históricas, 1934 .

Carvalho, José Murilo de. Ouro, terra e ferro: vozes de Minas. In: GOMES, Angela de Castro. Minas e os fundamentos do Brasil moderno. Belo Horizonte: Editora da UFMG, 2005 .

DiAs, Fernando Correia. Ouro Preto: território da palavra - Instituições e práticas intelectuais. Oficina do Inconfidência: Revista de Trabalho, Ouro Preto, ano 2, n. 1, 2001.

Egleaton, Terry. The idea of culture. Nova Jersey: John Wiley \& Sons, 2013.

Fonseca, Cláudia Damasceno. Arraiais e vilas d'el rei: espaço e poder nas Minas setecentistas. Belo Horizonte: Editora da UFMG, 2011.

Foucault, Michel. Outros espaços. In: Foucault, Michel. Estética: literatura e pintura, música e cinema. Organização de Manoel Barros da Motta. Tradução de Inês Autran Dourado Barbosa. Rio de Janeiro: Forense, 2009. (Coleção Ditos \& Escritos).

FREYRE, Gilberto. Interpretação do Brasil: aspectos da formação social brasileira como processo de amalgamento de raças e culturas. Tradução de Olívio Montenegro. Rio de Janeiro: José Olympio, 1947.

Frieiro, Eduardo. O diabo na livraria do Cônego. São Paulo: Edusp; Belo Horizonte: Itatiaia, 1981.

Garcia, Juliane Martins. Traços hispânicos no processo de latinidade da arquitetura colonial em Minas Gerais. 2005. Dissertação (Mestrado em Arquitetura) - Universidade Federal de Minas Gerais, Belo Horizonte, 2005.

LÉvi-Strauss, Claude. Natureza e cultura. In: LÉvi-Strauss, Claude. As estruturas elementares do parentesco. Tradução de Mariano Ferreira. Petrópolis: Vozes, 1982.

LibBy, Douglas Cole. As populações escravas das Minas setecentistas: um balanço preliminar. In: Resende, Maria Efigênia Lage de; Vilalta, Luiz Carlos (Org.). História de Minas Gerais: as Minas setecentistas. Belo Horizonte: Autêntica, 2007. v. 1. Lima Júnior, Augusto de. O Aleijadinho e a arte colonial. Rio de Janeiro: Edição do Autor, 1942. 
Lima, Alceu Amoroso. Voz de Minas: ensaio de sociologia regional brasileira. Petrópolis: Vozes, 2000.

Lima, Lezama. A expressão americana. Tradução de Irlemar Chiampi. São Paulo: Brasiliense, 1988.

LuKÁcs, Georg. Estética. Tradução de Manuel Sacristán. Barcelona: Grijalbo, 1967.

Machado, Lourival Gomes. Barroco mineiro. Organização de Francisco Iglésias. São Paulo: Perspectiva, 1991.

Maravall, José Antonio. A cultura do barroco. Tradução de Silvana Garcia. São Paulo: Edusp; Imprensa Oficial, 1997.

Maxwell, Kenneth. A devassa da devassa: a Inconfidência Mineira - Brasil e Portugal (1750-18o8). Tradução de João Maia. São Paulo: Paz e Terra, 2000.

Maxwell, Kenneth. Conjuração mineira: novos aspectos. Estudos Avançados, São Paulo, v. 3, n. 6, maio/ago. 1989.

Moraes, Fernanda Borges de. De arraiais, vilas e caminhos: a rede urbana das Minas coloniais. In: Resende, Maria Efigênia Lage de; Vilalta, Luiz Carlos (Org.). História de Minas Gerais: as Minas setecentistas. Belo Horizonte: Autêntica, 2007. v. 1.

Oliveira, Anelito de. A condição mineira: Drummond e a cultura do barroco. Revista USP, São Paulo, n. 114, p. 159-170, 2017.

Panofsky, Erwin. Idea: a evolução do conceito de belo. Tradução de Paulo Neves. São Paulo: Martins Fontes, 2000.

RANciÈre, Jacques. O dissenso. In: Novaes, Adauto (Org.). A crise da razão. São Paulo: Companhia das Letras, 2006.

RESENDE, Maria Efigênia Lage de. Itinerários e interditos na territorialização das Geraes. In: Resende, Maria Efigênia Lage de; Vilalta, Luiz Carlos (Org.). História de Minas Gerais: as Minas setecentistas. Belo Horizonte: Autêntica, 2007. v. 1.

Ribeiro, Darcy. O povo brasileiro: a formação e o sentido do Brasil. São Paulo: Companhia das Letras, 1997.

RouAnet, Sérgio Paulo. As Minas iluminadas: a Ilustração e a Inconfidência. In: Novaes, Adauto (Org.). Tempo e história. São Paulo: Companhia das Letras, 1992.

Santiago, Silviano. A construção de Aleijadinho. O Estado de S. Paulo, São Paulo, 15 jan. 2017. Disponível em: <https://goo.gl/wHgnvw>. Acesso em: 13 nov. 2017.

SAntos, Milton. A natureza do espaço: técnica e tempo, razão e emoção. São Paulo: Hucitec, 1996.

Santos, Milton. Pensando o espaço do homem. São Paulo: Hucitec, 1991. 
Silva, Joaquim José da. Tratado de geografia descritiva especial da província de Minas Gerais. Belo Horizonte: FJP, 1997.

SouzA, Laura de Mello e. Cláudio Manuel da Costa: o letrado dividido. São Paulo: Companhia das Letras, 2011.

TeixeIrA, Ivan. Mecenato pombalino e poesia neoclássica. São Paulo: Edusp, 1999.

Williams, Raymond. A produção social da escrita. Tradução de André Glaser. São Paulo: Unesp, 2014.

Williams, Raymond. Cultura e sociedade. Tradução de Leônidas H. B. Hegenberg et al. São Paulo: Nacional, 1969.

WöLflin, Heinrich. Renascença e barroco: estudo sobre a essência do estilo barroco e sua origem na Itália. Tradução de Mary Amazonas Leite de Barros e Antonio Steffen. São Paulo: Perspectiva, 1989.

Recebido em 18 de novembro de 2017.

Aprovado em 13 de abril de 2018.

\section{Resumo/Abstract/Resumen}

O manto de aporias: cultura, território e barroco na dinâmica sociohistórica do Estado de Minas Gerais

\section{Anelito de Oliveira}

Este artigo propõe uma interpretação da relação entre literatura e barroco em Minas Gerais, no período que se estende do século XVIII ao XX, a partir da elucidação do antagonismo evidente entre cultura e território, de que a obra atribuída a Antonio Francisco Lisboa, o Aleijadinho, diretamente vinculada à produção da cidade, é referência. Trata-se de exploração de base epistemológica, interessada numa teoria do conhecimento barroco, animada pela premissa de que a complexidade constitutiva do "barroco mineiro" deriva de seu estatuto histórico não exclusivamente artístico, de seu vínculo com a dinâmica social, com a questão urbana nas Minas coloniais. Pretende-se contribuir, sobretudo, para a superação de uma narrativa sobre o "barroco mineiro" esteticista, tanto quanto historicista, que o coloca como capital cultural resolvido, não como problema histórico inscrito na dinâmica sociopolítica brasileira, não apenas mineira.

Palavras-chave: Barroco, cultura, território, Minas Gerais, literatura 
The mantle of aporias: culture, territory and baroque in the sociohistorical dynamics of the State of Minas Gerais

\section{Anelito de Oliveira}

This article proposes an interpretation of the relationship between literature and baroque in Minas Gerais, in the period extending from the XVIII to the XX century, from the elucidation of the evident antagonism between culture and territory, that the work attributed to Antonio Francisco Lisboa, the Aleijadinho, directly linked to the production of the city, is a reference. It is an exploration of an epistemological basis, interested in a baroque theory of knowledge, animated by the premise that the constituent complexity of the "Barroco Mineiro" derives from its historical status, not exclusively artistic, from its link with social dynamics, with the urban question in colonial Minas state. It is intended to contribute, above all, to the overcoming of a narrative about the "Barroco Mineiro" estheticist as well as historicist, which places it as a cultural capital solved, not as a historical problem inscribed in the Brazilian sociopolitical dynamics, not only in Minas Gerais.

Keywords: Baroque, culture, territory, Minas Gerais, literature.

El manto de aporías: cultura, territorio y barroco en la dinámica sociohistórica del Estado de Minas Gerais

\section{Anelito de Oliveira}

Este artículo propone una interpretación de la relación entre la literatura y el barroco en Minas Gerais, en el período que se extiende entre los siglos XVIII y XX, a partir de la elucidación del antagonismo evidente entre cultura y territorio, situación que tiene en la obra atribuida a Antonio Francisco Lisboa, Aleijadinho, directamente relacionada con la producción de la ciudad, su gran referencia. Esta exploración es de naturaleza epistemologica, interesada en la elaboración de una teoría del conocimiento barroco, animada por la hipótesis de que la complejidad constitutiva del "Barroco Mineiro" resulta de su status quo histórico, no exclusivamente artistico, de su relación con la dinámica social y con la cuestión urbana en las Minas coloniales. Este trabajo intenta, especialmente, ofrecer elementos para la superación de una narrativa esteticista e historicista sobre el "Barroco Mineiro", responsable de su presentación como un capital cultural solucionado y no como un problema histórico presente en la dinámica sociopolítica brasileña, no solo en Minas Gerais.

Palabras clave: Barroco, cultura, territorio, Minas Gerais, literatura. 